\title{
Nobreza e Servidão em Nietzsche: um desafio ético para a Psicologia Social
}

\author{
Nilson Fernandes Dinis \\ Universidade Federal do Paraná
}

\begin{abstract}
Resumo
Na visão da filosofia de Nietzsche, a Ética é obediência aos costumes, é obediência cega à tradição. Portanto, seu novo projeto ético é um homem que em tudo quer depender apenas de si e não de uma tradição. Viver é o valor dos valores que não pode se curvar aos valores de nenhuma outra moral. Nietzsche parece ser um bom aliado para o trabalho social do psicólogo. Ele nos faz rever nosso próprio sistema de valores, já que muitas vezes o trabalho da Psicologia se vê tentado à normatização e socialização de grupos desviantes.

Palavras-chave: ética; Nietzsche; psicologia social; assistência à infância e à adolescência.
\end{abstract}

\begin{abstract}
Nobility and serfdom in Nietzsche: an ethical endeavour to social psychology

From the point of view of Nietzsche's philosophy, Ethics is obedience to customs, and a blind obedience to tradition. That is why his ethical project is of a man who wants to depend only on himself, and not on a tradition. To live is a value which doesn't bow to the values of any other moral concept. Nietszche seems to be a good partner to the social practice of the psychologist. He makes us review our value concepts, for often psychological practice is tempted to follow norms and socialization of deviant groups.
\end{abstract}

Keywords: ethics; Nietzsche; social psychology; child and adolescent assistance.

O tema proposto para este artigo nos traz um paradoxo imediato: como pensar um possível conceito de ética para a prática social da Psicologia em Nietzsche (que é um filósofo, não um psicólogo especializado), cuja filosofia visa justamente questionar os conceitos de eticidade e moralidade? Seria possível pensarmos a ética em uma filosofia que procura se situar além dos conceitos de bem e mal?

Trilhando pelos caminhos da filologia, Nietzsche nos coloca em contato com as raízes dos conceitos que investiga, entre eles, os conceitos de Moralidade, Eticidade e a própria noção de Sujeito. Na sua transvaloração de todos os valores, a busca da verdade será a própria crítica da idéia de verdade tida como um valor absoluto. Um dos pontos principais na crítica nietzscheana é se a ascese ao mundo da Razão, da Verdade e da Moralidade é potencializadora ou não da Vida: o 'valor dos valores'. Portanto as questões que aparecem já no prólogo de sua Genealogia da Moral são: "sob que condições o homem inventou para si os juízos de valor 'bom' e 'mau'? e que valor têm eles? Obstruíram ou promoveram até agora o crescimento do homem?" (Nietzsche, 1998, p. 191).

Entre as obras de Nietzsche que procuram denunciar a função utilitária de valores como Razão, Verdade e Moralidade quando se impõem como valores universais estão Para Além de Bem e Mal e
Para a Genealogia da Moral, que buscam a historicidade destes valores. São alguns dos textos nos quais iremos centrar nossa atenção para tentarmos pensar um possível conceito ético nietzscheano.

\section{MORAL NOBRE E MORAL ESCRAVA}

Uma das primeiras referências sobre os conceitos de moral nobre e moral escrava aparece no capítulo "O que é nobre" em Para Além de Bem e Mal:

Há uma moral de senhores e uma moral de escravos (...) No primeiro caso, quando os dominantes determinam o conceito de "bom”, são os estados de alma elevados e orgulhosos que são considerados distintivos e determinantes da hierarquia. $O$ homem nobre afasta de si os seres nos quais se exprime o contrário desses estados de elevação e orgulho; ele os despreza (Nietzsche, 1992, p. 172).

No homem nobre está a origem do valor bom, sendo que ruim é sempre seu oposto, ou seja, o escravo: "Note-se que nesta primeira espécie de moral a oposição 'bom' e 'ruim' significa tanto quanto 'nobre' e 'desprezível': - a oposição 'bom' e 'mau' tem outra origem" (1992, p. 172). Na moral nobre o homem é criador, cria valores que atribui a si mesmo, 
como dirá Nietzsche "uma semelhante moral é glorificação de si”. Já para com a moral escrava as palavras de Nietzsche são absolutamente implacáveis:

A moral de escravos é essencialmente uma moral de utilidade. Aqui está o foco de origem da famosa oposição 'bom'e 'mau' - no que é mau se sente poder e periculosidade, uma certa terribilidade, sutileza e força que não permite o desprezo. Logo, segundo a moral dos escravos, o 'mau' inspira medo; segundo a moral dos senhores é precisamente o 'bom' que desperta e quer despertar medo, enquanto o homem 'ruim' é sentido como o desprezivel (...) porque em todo caso o bom tem de ser, no modo de pensar escravo, um homem inofensivo: é de boa índole, fácil de enganar, talvez um pouco estúpido, ou seja, um bonhomme [um bom homem]. Onde quer que a moral de escravos se torne preponderante, a língua tende a aproximar as palavras 'bom' $e$ 'estúpido' (Nietzsche, 1992, p. 174-175).

Ressalta-se neste parágrafo os caminhos da pesquisa filológica de Nietzsche quando tenta apontar a origem dos conceitos 'bom' e 'mau'. Tal análise será ainda retomada na 1a. dissertação da Genealogia e no parágrafo 11 da $2 a$. dissertação. Essa análise pode ser reforçada se pensarmos que na língua alemã a palavra 'gut' serve para designar 'bom', enquanto que 'schlecht' é a palavra para 'ruim' e 'böse' para 'mau'. Mesmo em português a palavra 'mau' parece conotar um sentido mais intenso e pesado que 'ruim'. Ruim, para a forma nobre de avaliar, é apenas um pálido contraste ao conceito de bom que reserva para si. Seu movimento primeiro é afirmativo. Mau, para o escravo, concentra os sentimentos de raiva e inveja que sente com relação ao nobre, só depois é que cria um 'bom' para contrapor a este 'mau' externo. Assim, seu movimento primeiro é negativo em relação a um fora , para só depois buscar sua auto-afirmação.

Enquanto toda moral nobre nasce de um triunfante Sim a si mesma, já de início a moral escrava diz Não a um 'fora', um 'outro', um 'não-eu' - e este Não é seu ato criador (...) este necessário dirigirse para fora, em vez de voltar-se para si - é algo próprio do ressentimento (...) O contrário sucede no modo de valoração nobre: ela age e cresce espontaneamente, busca seu oposto somente para dizer Sim a si mesmo com ainda maior júbilo $e$ gratidão (Nietzsche, 1998, p. 29).

O poder da moral escrava nasce desta força reativa que instituirá valores como a Moral, a Religião, Deus, a Verdade e a Razão como sendo valores universais, contra os quais se coloca o martelo filosófico de Nietzsche na sua análise genealógica. Algumas vezes sua visão é extremamente pessimista: "Sujeitemo-nos aos fatos: o povo venceu - ou 'os escravos', ou 'a plebe' ou 'o rebanho', ou como quiser chamá-lo (...) Ao mesmo tempo essa vitória pode ser tomada como um envenenamento do sangue (...) tudo se judaíza, cristianiza, plebeíza visivelmente..." (Nietzsche, 1998, p. 28).

Destas passagens se servirão certos intérpretes para aproximar o pensamento nietzscheano do movimento anti-semita. Porém, nada está mais distante da interpretação nietzscheana. Ao contrário de um possível preconceito étnico, a mensagem nietzscheana é bem clara:

Há uma moral de senhores e uma moral de escravos; acrescento de imediato que em todas as culturas superiores e mais misturadas aparecem também tentativas de mediação entre as duas morais, e, com ainda maior freqüência, confusão das mesmas e incompreensão mútua, por vezes inclusive dura coexistência - até mesmo num homem, no interior de uma só alma (Nietzsche, 1992, p. 172).

Mas enfim o que é para Nietzsche o conceito de Moralidade ou de Eticidade? Para isso vamos visitar a Aurora, onde Nietzsche expõe seu pensamento sobre os preconceitos morais e sua posição em relação ao conceito de eticidade:

...eticidade não é nada outro (portanto em especial, nada mais!) do que obediência a costumes, seja de que espécie forem; e costumes são o modo tradicional de agir e de avaliar. Em coisas onde nenhuma tradição manda não há nenhuma eticidade. O homem livre é não ético, porque em tudo quer depender de si e não de uma tradição (...) $O$ que é a tradição? Uma autoridade superior, a que se obedece, não porque ela manda fazer o que nos é útil, mas porque ela manda (Nietzsche, 1978b, p. 159).

Um cuidado deve-se ressaltar no estilo categórico de Nietzsche em relação ao conceito de eticidade. Ainda em Aurora, Nietzsche esclarecerá que sua desconfiança em relação ao conceito de eticidade se pauta na recusa de que os juízos éticos repousem em verdades universais. Assim negar os pressupostos universais da ética implicaria também negar os pressupostos universais de um comportamento reativo oposto que se constitua em uma ineticidade. Como ressalta Nietzsche:

Não nego, como se entende por si mesmo pressuposto que não sou nenhum parvo -, que muitas ações que se chamam não-éticas devam ser evitadas, combatidas; do mesmo modo, que muitas que se chamam éticas devam ser feitas $e$ propiciadas, mas penso: em um como no outro caso, por outros fundamentos do que até agora (Nietzsche, 1978b, p. 169).

Talvez o projeto nietzscheano seja exatamente pensar novos pressupostos para ética que não se pautem nos pressupostos universais de uma obediência cega à tradição, mas na capacidade de 
reavaliarmos os valores a partir da genealogia o que possibilitará ao "homem livre" a liberdade de escolher os valores mais condizentes com um exercício de afirmação da vida. Uma ética fundamentada não em uma vontade universal de verdade, mas em uma vontade de potência, hipótese que desenvolveremos mais adiante.

Por outro lado não podemos deixar de lembrar que Eticidade ou Moralidade remetem também etimologicamente às suas raízes: ethos em grego e mores em latim, as duas com o significado usual de costume. A tradição, autoridade que se obedece apenas pelo movimento cego de se obedecer, ou de pertencer a um grupo social. Seria um valor condizente com a afirmação da vida? É por isso que, em sua Genealogia da Moral, Nietzsche procurará questionar os valores universais impostos pela tradição. Apesar disto, podemos pensar que Nietzsche, mesmo desconfiando de palavras como 'moralidade', 'eticidade', 'bom e mau', tenha o seu próprio conceito de 'bom'. Podemos detectar nos textos nietzscheanos verdadeiras exortações a determinados tipos de comportamento. Recorrendo a estas passagens é que tentaremos pensar um possível conceito de 'ética' em Nietzsche.

\section{ETERNO RETORNO DO MESMO E DO OUTRO: UMA POSSIBILIDADE PARA A ÉTICA?}

O primeiro caminho que buscamos foi trilhando pelos textos da pesquisadora brasileira Scarlett Marton. Um desses textos traz um título bastante provocativo para nosso tema: O Eterno Retorno do Mesmo - tese cosmológica ou imperativo ético?. A base da argumentação de Marton, para sustentar a tese de um possível eterno retorno do Mesmo em Nietzsche, pode ser encontrada na própria teoria nietzscheana das forças cosmológicas:

Se o mundo pode ser pensado como grandeza determinada de força (...) disso se segue que ele tem de passar por um número calculável de combinações, no grande jogo de dados de sua existência. Em um tempo infinito, cada combinação possível estaria alguma vez alcançada; mais ainda; estaria alcançada infinitas vezes. E como entre cada combinação e seu próximo retorno todas as combinações ainda possiveis teriam de estar transcorridas e cada uma dessas combinações condiciona a seqüência inteira das combinações da mesma série, com isso estaria provado um curso circular de séries absolutamente idênticas: o mundo como curso circular que infinitas vezes já se repetiu e que joga seu jogo in infinitum... (Nietzsche, 1978d, p. 396397).

O número de combinações das forças é finito, e o tempo é infinito, logo segue-se que no decorrer infinito do tempo as combinações das forças (cuja diversidade é grande, porém finita) tendem fatalmente a se repetir em algum momento. Com tais dados temos a tese do eterno retorno do Mesmo. Por outro lado, Marton nos aponta passagens em que há toda uma exortação nietzscheana a vivermos de acordo com o eterno retorno. Como exemplo, temos a seguinte passagem de sua própria tradução:

Minha doutrina diz: a tarefa consiste em viver de tal maneira que devas desejar viver de novo - tu viverás de novo de qualquer modo! Aquele a quem o esforço proporciona o mais alto sentimento, que se esforce, aquele a quem o repouso proporciona $o$ mais alto sentimento que repouse (...) Possa tornar-se consciente do que lhe proporciona $o$ mais alto sentimento e não recuar diante de nenhum meio! A Eternidade está em jogo! (Marton, 1992, p. 209).

Mas há uma certa contradição em tal pensamento. Por que há a exortação de Nietzsche a vivermos de acordo com o eterno retorno se o eterno retorno independe de nossa vontade? Seria então o eterno retorno apenas uma exortação ética? Porém nosso objetivo não será o de solucionarmos tal paradoxo. Acreditamos poder buscar outras referências para pensarmos uma possível ética na filosofia de Nietzsche.

Antes, porém, consultemos uma outra interpretação do eterno retorno em Nietzsche, a do filósofo Gilles Deleuze, que procura colocar o eterno retorno como o eterno retorno do diferente, ou seja, um eterno retorno do Outro, do Devir. Aqui a tese cosmológica de Marton cede lugar a uma ontologia da diferença:

Retornar é precisamente o ser do devir, o uno do múltiplo, a necessidade do acaso. Assim, é preciso evitar fazer do eterno Retorno um retorno do Mesmo (...) Não é o mesmo que volta, já que o voltar é a forma original do mesmo, que apenas se diz do diverso, do múltiplo, do devir. O Mesmo não volta, é o voltar apenas que é o Mesmo daquilo que devém (Deleuze, 1985, p. 30).

Na filosofia deleuziana, onde todas as identidades são transitórias, a única coisa que retorna é o Devir, ou seja, o 'ser diferente'. Ainda na leitura deleuziana o eterno retorno tem mesmo é um impacto seletivo:

O segredo de Nietzsche é que o eterno Retorno é seletivo (...) Encontra-se eliminado o mundo dos 'semiquereres', tudo o que queremos com a condição de dizer: uma vez, nada senão uma vez. Mesmo uma covardia, uma preguiça que queira seu eterno retorno tornar-se-ia outra coisa diferente de uma preguiça, de uma covardia: tornar-se-iam activas e potências de afirmação (Deleuze, 1985, p. 31). 
Através da leitura deleuziana podemos perceber um Nietzsche que privilegia a afirmação da vida, e a afirmação da vida para Deleuze é o próprio retorno da diferença: "Só volta a afirmação, só volta aquilo que pode ser afirmado, só a alegria volta. Tudo o que pode ser negado, tudo o que é negação é expulso pelo próprio movimento do eterno Retorno" (Deleuze, 1985, p. 32).

Eterno retorno do Mesmo ou eterno retorno do Outro? Talvez possamos fugir desta controvérsia. A passagem pelas interpretações de Marton e Deleuze, no entanto, nos possibilitou refletir sobre o peso do conceito de Eterno Retorno e as conseqüências éticas que poderiam advir de tal pensamento. Observação esta já feita por Nietzsche:

Se esse pensamento tomasse conta de ' $t i$ ', tal como você é, ele o transformaria e o esmagaria talvez; a questão em tudo e em cada coisa: 'Você quer isso mais uma vez e por incontáveis vezes?', pesaria sobre os seus atos como o maior peso! (Nietzsche, 2001, p. 230).

Não querendo entrar na polêmica das diferentes leituras sobre o eterno retorno, buscaremos então um outro caminho para pensar um possível conceito de eticidade em Nietzsche. Poderíamos pensar se a moral nobre não seria uma espécie de princípio ético em Nietzsche? Mas sempre pensando as figuras do nobre e do escravo como metáforas, circuitos de forças que estiveram presentes nos processos de subjetivação que permeiam todas as culturas, e que podem brigar incansavelmente no interior de uma mesma alma, de um mesmo homem.

A moral nobre nos parece, em nossa leitura do projeto nietzscheano, como sendo uma busca da afirmação da vontade de potência, ou seja, o movimento mais condizente com a afirmação da Vida, justamente porque ela se comunica com as forças vitais do homem. Ela faz com que ele se meça não pelos valores superiores e universais impostos pela tradição, mas pelo que realmente ele pode e é capaz de realizar frente ao mundo. Já a moral escrava, como se apóia na busca de valores superiores ou transcendentes, que se encontram além da sua capacidade efetiva de se afirmar frente ao mundo por um outro caminho que não seja a reação, seria uma das forças mais antagônicas à expansão da Vida. Assim contra a moral ressentida dos escravos que teme a vida, o desejo, as pulsões, se ergue a moral nobre que se apóia nos instintos vitais, nas paixões, no desejo que Nietzsche chama de vontade de potência.

Em Nietzsche a vontade de potência significa a Vida no sentido pré-socrático de physis: a totalidade de tudo o que existe. Mas significa também uma crítica ao mundo das identidades estáveis, o sujeito passa a ser compreendido não mais como uma unidade substancial, mas um fenômeno múltiplo a partir do jogo incessante de diferentes impulsos e forças. Assim entender a vontade como uma vontade racional, ou como algo emanando da ação de um pressuposto sujeito seria um equívoco, como também seria um equívoco entender o poder como uma instância única superior exercendo seu domínio. A vontade de poder ou vontade de potência é a vida enquanto pluralidade de forças que se direcionam em todos os sentidos, e o mundo constitui-se dessa mesma rede de forças que pode aumentar tornando a vida mais potente e saudável, mas também pode diminuir, enfraquecendo e adoecendo a própria vida. Longe de ser regida por leis ou por uma vontade racional, a vontade de potência é regida pelo acaso. É $\mathrm{o}$ acaso que dirige o seu jogo das forças. Portanto o homem ativo é aquele que não se deixa conduzir por significados fixos da realidade, mas é aquele que afirma a existência do acaso, seu desejo nunca é um desejo de conservação, mas um desejo de expansão da vida, de retorno de mais força, de mais potência. Essa é também a leitura de Deleuze quando pensa o eterno retorno em Nietzsche como sendo o eterno retorno da diferença. Na sua ontologia da diferença o sujeito está sempre a devir, sempre em expansão, sempre se comunicando com forças que o arrastam para o além do humano e a função seletiva do eterno retorno é justamente de separar as forças afirmativas que visam à expansão da vida, das forças reativas que visam a sua conservação. Desta forma, a vontade de potência também não se confunde com uma vontade de existência (que seria uma forma de conservação da vida), ela será sempre uma vontade de superação de si:

Não atingiu a verdade, por certo, quem atirou em sua direção a palavra da 'vontade de existência': essa vontade - não há! Pois o que não é, não pode querer; mas o que está na existência, como poderia ainda querer vir à existência. Somente onde há vida, há também vontade: mas não vontade de vida, e sim - assim vos ensino vontade de potência! Muito, para o vivente, é estimado mais alto do que o próprio viver, mas na própria estimativa fala - a vontade de potência! (Nietzsche, 1978a, p. 238-239).

Parece-nos assim bastante provável que Nietzsche se coloque a favor da moral nobre enquanto movimento de afirmação da vontade de potência e que, ao mesmo tempo, tivesse um certo olhar de desdém com relação à moral escrava. Além disso, ao final da primeira dissertação da Genealogia, a posição de Nietzsche é clara: “...supondo que há muito tenha ficado claro o que pretendo, o que desejo com a perigosa senha inscrita na fronte do meu último livro 'Além do bem e do mal'... Ao menos isto não significa 'Além do bom e do ruim"' (Nietzsche, 1998, p. 45). Ora, a opção pelos valores 'bom e ruim', forma de expressão dos valores nobres, como nos aponta a própria Genealogia, ao contrário de 'bom e mal', forma de expressão dos valores do ressentimento, nos diz do lugar de Nietzsche quando pensa a afirmação da vida.

Portanto, para nossa leitura, a questão de um eterno retorno do Mesmo ou um eterno retorno do Outro recebe um outro encaminhamento. Se o princípio ético 
é a forma nobre de avaliar ou de viver, só temos que pensar no que vem afirmar ou não a vida, na pergunta fatal que pode se tornar o mais pesado dos pesos tendo o poder de transformar o destino dos homens, selecionando os mais fortes dos mais fracos: 'Quero isto ainda uma vez e ainda inúmeras vezes ?'. E a vontade nobre é aquela que reverte tudo a seu favor, tudo pelo movimento de afirmação da vida, é aquela que caminha para a redenção que aparece em Zaratustra: "Redimir o que passou e recriar todo 'Foi' em um 'Assim eu quis!' , somente isto se chamaria para mim a redenção" (Nietzsche, 1978a, p. 247)

O nobre procurará viver intensamente o presente. Seja em um eterno retorno do mesmo, ou o eterno retorno do diferente, ele sempre reverterá a seu favor. Em um eterno retorno do Mesmo a vontade nobre se realiza porque pode dizer: quero ainda mais uma vez este momento porque nele fiz o meu máximo! Já na moral escrava a repetição não demora a formar a equação: repetição $=$ vida $=$ tédio. Como não sabe viver o presente, o escravo espera um futuro que possa vir a ser diferente, se apóia portanto, em um valor transcendente ao momento efetivo no qual vive. E se não há chances futuras de mudança ainda lhe resta a esperança cristã de uma outra vida!

Tentemos agora imaginar o curso do pensamento dessas duas formas tão diferentes de avaliar frente a um possível eterno retorno do diferente. Se as coisas devêm, se elas vêm e se perdem, o homem nobre procurará também tirar delas o seu máximo. Ele sabe viver esse tempo fugaz na perspectiva daquilo que o filósofo Deleuze chamaria de um 'finito-ilimitado' , mas que podem ser resumidas nas palavras de um dos nossos maiores poetas: "que seja infinito enquanto dure". O pensamento escravo, na impotência de reter o que passa, concluirá pela efemeridade das coisas e pela futilidade da vida, assim ficará na espera por uma Eternidade que possa vir redimi-lo do imperfeito simulacro que é a Vida. Se refugiará portanto, mais uma vez, em seus valores transcendentes.

\section{NORMATIZAÇÃO E RESISTÊNCIA: A PRÁTICA SOCIAL DO PSICÓlOGO}

Para considerações finais vamos pensar as conseqüências dessa nova ética de afirmação da vida no trabalho social da Psicologia Para isso escolhemos cartografar o trabalho com grupos considerados marginais, mais especificadamente, com crianças e adolescentes em situação de rua. Ora, Nietzsche nos parece um autor bem apropriado para pensar esse novo modelo de subjetivação: a produção de uma nova subjetividade que se configura no espaço aberto das ruas das grandes cidades e a rede de relações que este novo espaço geográfico permite ou limita. Uma experimentação diária em contato com o corpo do outro testando suas possibilidades e limites. Sempre desafiando e questionando a onipresença de uma moral única que permeia as relações sociais com dogmatismos que condicionam as ações humanas a padrões rígidos de comportamento. Dessa forma o psicólogo deve buscar o oposto, ou seja, a possibilidade de recriar as relações humanas com base em outros fundamentos, manifestar o desejo permanente de renovação criativa das possibilidades humanas. Não mais a ética no sentido de um dever ser de todas as coisas, mas a ética do cuidado de si, de uma estética do viver. No projeto ético-estético nietzscheano, viver é o valor dos valores que não pode se submeter às convenções de nenhuma outra moralidade. Ao invés da ética universal de Hegel, a produção de um viver e saber sempre perspectivista, como na estética do poeta Fernando Pessoa: "sentir tudo de todas as maneiras, viver tudo de todos os lados". Poder enfim reconhecer a vida em suas diversas fontes.

A subjetividade produzida por meninos e meninas estruturados nas ruas é geralmente vista, pelo psicólogo, como um espaço de exterioridade com demandas ligadas a um imediatismo sempre oposto ao espaço da subjetividade privada, que freqüenta nossos consultórios. Assim a tentação do psicólogo é normatizar essa forma desviante, "fazer contratos", trazê-la novamente para o seio da sociedade através de uma eficiente administração disciplinar do seu tempo, sejam as práticas educativas de trabalho, esporte ou mesmo das artes. Não queremos com isso menosprezar a prática de esportes ou da arte como auxiliar nos projetos educativos, mas apenas questionar se seu uso é realmente a busca de novas formas de expressão para uma subjetividade que se caracteriza justamente pelo desejo de potência, ou se é apenas mais uma forma sofisticada de domesticar o corpo, disciplinar o tempo, apaziguar o mal-estar provocado pelo encontro com um espelho pouco generoso de nós mesmos?

Uma prática socioeducativa quase sempre consiste em ocupar o tempo ocioso, transformar o inútil em útil, reeducar o corpo, trazê-lo para o espaço da visibilidade controlada: a escola e a fábrica. Livrá-lo da visibilidade não controlada e imprevisível da rua. Mas poderíamos perguntar com Nietzsche: que é socializar senão obedecer cegamente à tradição? Quando tais práticas socioeducativas fracassam o que mais acontece é o retorno para as ruas, mas com um corpo já docilizado, com um corpo que perdeu a agressividade natural que antes lhe servia como mecanismo de defesa. E o que é mesmo uma prática socioeducativa? Adjetivo tão presente no discurso dos pedagogos e dos psicólogos sociais! Inspirados por Nietzsche, que busca a origem dos conceitos que trabalha, vamos examinar provocativamente tal conceito.

Parece-nos que o adjetivo socioeducativo se torna mais presente nos nossos discursos a partir do Estatuto da criança e do adolescente dos anos 90. E medidas socioeducativas, segundo o mesmo Estatuto, são medidas disciplinares, aplicáveis quando há prática de ato infracional e incluem medidas como a advertência, a obrigação de reparar o dano, a prestação de serviços à comunidade, a liberdade assistida, a inserção em regime de semiliberdade, a internação em estabelecimento educacional etc... O trabalho com crianças e adolescentes em situação de rua é afinal um trabalho educativo ou socioeducativo? Educar para quem? Será que o trabalho com crianças e 
adolescentes em situação de rua deve ter correspondências com medidas disciplinares? A opção recaíra sobre a escolha ética de cada psicólogo! É aqui o momento em que revemos nossos conceitos éticos com Nietzsche: socializar obedecendo à tradição ou investir em novas formas desejantes de resistência, mas, ao mesmo tempo, tentando encontrar alternativas para o dilema: normatização ou integração?

A rua pode ser uma alternativa, um espaço da malandragem criativa que permite escapar dos modelos de homogeneização impostos pela sociedade de controle, mas pode tornar-se também um meio que se envereda sem retorno por caminhos de destruição e morte. É na tentativa de evitar esse desvio que deveria se situar o trabalho do psicólogo. Não através da produção de corpos dóceis e eficientes, mas respeitando as singularidades, e investindo na descoberta de novas formas de resistência que, na busca de um efetivo exercício de liberdade, possam novamente pactuar com as forças afirmativas da vida.

Um trabalho incômodo para os que preferem a eficiência e a segurança dos resultados imediatos das práticas docilizadoras, mas para os outros, psicólogosandarilhos também capturados pela paixão nômade pela vida, um desafio na busca de soluções criativas e um exercício de revisão constante, para evitar cair em práticas normatizadoras, buscando novos caminhos para além dos valores escravos, viver além de 'bem' e 'mal'!

O andarilho. - Quem chegou, ainda que apenas em certa medida, à liberdade da razão, não pode sentir-se sobre a Terra senão como andarilho embora não como viajante em direção a um alvo último: pois este não há. Mas bem que ele quer ver $e$ ter os olhos abertos para tudo o que propriamente se passa no mundo, por isso não pode prender seu coração com demasiada firmeza a nada de singular; tem de haver nele próprio algo de errante, que encontra sua alegria na mudança e na transitoriedade (Nietzsche, 1978c, p. 118).

\section{REFERÊNCIAS}

Deleuze, G. (1976). Nietzsche e a Filosofia. Rio de Janeiro: Ed. Rio.

Deleuze, G. (1985). Nietzsche. Lisboa: Edições 70.

Lebrun, G. (1988). O Avesso da Dialética: Hegel à luz de Nietzsche. São Paulo: Companhia das Letras.

Machado, R. (1985). Nietzsche e a Verdade. Rio de Janeiro: Rocco.

Marton, S. (1982). Nietzsche: uma filosofia a marteladas. São Paulo: Brasiliense.

Marton, S. (1992). O Eterno Retorno do Mesmo: tese cosmológica ou imperativo ético?. Em A. Novaes (Org.), Etica (pp. 205-221). São Paulo: Companhia das Letras.

Marton, S. (1993). Nietzsche: a transvaloração dos valores. São Paulo: Moderna.

Nietzsche, F. W. (1978b). Aurora. Em F. W. Nietzsche, Obras incompletas (pp. 153-186). São Paulo: Abril Cultural.
Nietzsche, F. W. (1978). Obras incompletas. São Paulo: Abril Cultural.

Nietzsche, F. W. (1978a). Assim falou Zaratustra. Em F. W. Nietzsche, Obras incompletas (pp. 225-265). São Paulo: Abril Cultural.

Nietzsche, F. W. (1978c). Humano, demasiado humano. Em F. W. Nietzsche, Obras incompletas (pp. 83-151). São Paulo: Abril Cultural.

Nietzsche, F. W. (1978d). Sobre o niilismo e o eterno retorno. Em F. W. Nietzsche, Obras incompletas (pp. 377-397). São Paulo: Abril Cultural.

Nietzsche, F. W. (1986). Assim falou Zaratustra.: um livro para todos e para ninguém. Rio de Janeiro: Civilização Brasileira.

Nietzsche, F. W. (1992). Além do bem e do mal: prelúdio a uma filosofia do futuro. São Paulo: Companhia das Letras.

Nietzsche, F. W. (1998). Genealogia da Moral: uma polêmica. São Paulo: Companhia das Letras.

Nietzsche, F. W. (2001). A gaia ciência. São Paulo: Companhia das Letras. 


\section{Sobre o autor}

Nilson Fernandes Dinis: Professor adjunto na área de Psicologia da Educação no Departamento de Teoria e Fundamentos da Educação da Universidade Federal do Paraná e Doutor em Educação pela UNICAMP. E-mail: nfdinis@ hotmail.com. 